\title{
FUNCIONES EXTERNAS \\ EN LAS COMEDIAS DE ENREDO CALDERONIANAS
}

\author{
Erik Coenen \\ Universidad Complutense de Madrid \\ Instituto del Teatro de Madrid \\ Avenida Complutense, s.n. \\ 28040 Madrid \\ ewcoenen@ucm.es
}

INTRODUCCIÓN: FUNCIONES INTERNAS Y EXTERNAS DEL TEXTO DRAMÁTICO

En el teatro se producen dos hechos simultáneos, uno ficticio y otro real. En el mundo interno de la obra dramática, unos personajes actúan e interactúan —o creen hacerlo, tan firmemente como yo creo estar aquí escribiendo esta frase- espontáneamente y como les parezca oportuno. Al mismo tiempo, en el mundo externo a la obra dramática, unos espectadores de carne y hueso contemplan la representación de dicha obra por unos cuantos actores, tal como estos la han ensayado de antemano. La primera situación se produce, pongamos por caso, durante unos días de 1580 en el pueblo de Zalamea o en torno a 1930 en la vivienda de Bernarda Alba; la segunda, durante unas horas escasas en un teatro, una plaza u otro lugar acomodado para ello y en un horario de ocio también preestablecido para ello. Es crucial para el estudioso del teatro tener presente que la situación primera, la interna, ha sido diseñada por el autor teniendo siempre en cuenta su funcionalidad o eficacia para la segunda, la externa ${ }^{1}$. El autor concibe, selecciona y dispone las acciones

\footnotetext{
${ }^{1}$ Ya Ingarden (1958, p. 162), después de atribuir al discurso teatral cuatro funciones que yo llamaría todas internas, añade que «las palabras pronunciadas por los personajes deben cumplir otra función (de un tipo diferente) respecto al público». García Barrientos, por su parte, anota que «hablar de funciones "teatrales" significa ante todo
} 
de los personajes - entre las que suelen predominar las acciones verbales, es decir, el diálogo- para que un público los contemple realizándolas. Los personajes hacen lo que hacen porque el autor quiere que les veamos hacerlo y dicen lo que dicen porque el autor quiere que les oigamos decirlo. De modo que, por más que los propios personajes - es de suponer- crean estar viviendo sus vidas de acuerdo con su libérrimo albedrío, son, en realidad, como aquellas piezas de ajedrez en el soneto de Borges que «no saben que la mano señalada / del jugador gobierna su destino»: ignoran que su interacción y comunicación están al servicio de otro acto comunicativo, externo al drama, entre, por un lado, el autor (con su extensión en el director, los actores y todo su equipo) ${ }^{2}$, y por otro, el espectador, que es el «destinatario oculto» del diálogo teatral ${ }^{3}$.

Al inicio de la representación, ese destinatario oculto ignora todo de la obra salvo su título, y el autor y la compañía han de conseguir que, al final de la representación, ese mismo espectador haya llegado a saber todo lo que hay que saber para entender, valorar y experimentar emocionalmente con plenitud el espectáculo. Se trata, pues, al menos en una parte clave del arte teatral, de transmitir paulatinamente al público un conjunto importante de datos que configuran el universo interno de la obra ${ }^{4}$. Muchos de estos datos son conocidos por los personajes,

observar el diálogo en función del público, plantearse "para qué" dice tal o cual personaje lo que dice, no pensando en los otros personajes sino en el espectador que los observa" (2003, p. 58) y propone a continuación una clasificación de funciones externas (2003, pp. 58 y ss).

${ }^{2}$ Soy consciente de que no hago justicia aquí con la inmensa contribución al resultado artístico por parte de quienes intervienen entre el autor y el público para reforzar, realzar, enriquecer, o, a veces, modificar, deformar, sabotear o volver incoherente, aquello que el autor comunica al público por medio de su obra: productores, directores, escenógrafos, técnicos de luz y sonido, vestuaristas, los propios actores con su interpretación, en fin, todo el equipo involucrado en llevar a la escena la obra concebida por el autor. No obstante, estas personas aún no intervienen, y sólo participan in potentia, en los textos que estudiamos de los autores dramáticos clásicos; diría más bien que su trabajo ha de empezar precisamente con un análisis de la partitura dramática como el que propongo aquí para que su intervención en ella no la debilite ni contradiga.

${ }^{3}$ En término de Ubersfeld, 2004, p. 11.

4 «Dado que la obra parte, desde el punto de vista informativo, de cero, el diálogo es el medio más natural para transmitir la información necesaria y relevante al espectador [...]. Este principio exige progresión, orden, no contradicción en los datos y proporción o cantidad adecuada (la información ha de transmitirse en el momento preciso para provocar tensión, intriga, interés, comprensión del argumento o elaboración de un sentido global). Pero - y aquí radica una de las dificultades de la escritura teatral- esta 
que en este sentido parten con ventaja en comparación con el público, y es imprescindible saldar ese "déficit informativo». En las comedias de enredo ${ }^{6}$, que son las que me interesan aquí, se aspira incluso a invertir la situación inicial, haciendo al espectador testigo privilegiado de la creación de una confusión que a los propios personajes les resultará inexplicable, por lo que su perplejidad es contemplada con hilaridad por el espectador. Al principio de la función urge, pues, poner al público al tanto de los hechos básicos del mundo dramático representado, por lo que las escenas iniciales, que pueden llegar a abarcar todo el acto inicial, suelen estar diseñadas para exponer la situación dramática de manera eficaz pero también cuidadosamente dosificada, dados los límites a la capacidad de concentración y absorción de información por parte de los espectadores, así como la imposibilidad de recuperar información ya proporcionada anteriormente en el diálogo escénico (a diferencia de lo que sucede en la lectura). De ahí que, en términos de ritmo escénico, las escenas iniciales tienden a parecer más lentas, más verbales, menos densas en acción no verbal que las partes centrales y finales de la obra, para las que preparan.

Poner al alcance del público la información de la que ya disponen los personajes es una dificultad específica de la escritura dramática, y es que la inexistencia de una voz narrativa capaz de proporcionar esa información directamente obliga a deslizarla en el diálogo escénico, en textos cuya enunciación por parte de los personajes ha de resultar justificada dentro del mundo interno del drama. En tales casos, resulta relativamente fácil distinguir en el diálogo entre una función externa, orientada al público, y una función interna, de servir de vehículo de comunicación o de expresión aparentemente espontáneas a los personajes, aunque, como señala Ingarden, «las palabras pronunciadas deben

información no puede darse como tal, enunciándola, añadida por el autor o los personajes desde fuera, sino integrándola en la acción y la interrelación dialógica, surgiendo de ella» (Trancón, 2006, p. 179).

${ }^{5}$ En término de Spang, 1991, p. 84.

${ }^{6}$ No entraré en problemas de definición de la comedia de enredo. Señala Serralta (1988, pp. 125 y 128) que «todos tenemos la impresión de saber exactamente a qué tipo de piezas alude» el término, y aventura que su rasgo definidor consiste «no en la presencia — constante [en la comedia nueva] - del enredo, sino en su mayor o menor intensidad y complicación", rasgo que justifica la consideración de Calderón como el cultivador del subgénero por excelencia. 
cumplir armoniosamente el conjunto de funciones» ${ }^{7}$. En no pocos casos, la información orientada hacia la situación externa es insertada en aquella parte del enunciado que los lingüistas denominan el «tema»o el «topic»: la parte que para los interlocutores contiene información ya conocida, cuya mención es justificada por el «rema», el «comment» que se le adhiere; pero en tales casos, lo que para el personaje es mero tema, es rema para el público.

Pero no sólo se trata de poner remedio a un déficit informativo, sino también, y sobre todo, de exponer y plausibilizar el argumento de la obra. En el caso de las comedias de enredo, cuyo argumento no puede ser sino muy inverosímil, se hace especialmente delicada la tarea de disimular lo rebuscado de la trama, haciendo aparentar que los sucesos y acciones se sucedan unos a otros con cierta necesidad o al menos verosimilitud. En este aspecto, la función externa es hacer funcionar y avanzar el mecanismo de la trama sin que ello resulte excesivamente forzado en el plano interno de la comedia.

Si bien varios de los métodos de análisis de textos dramáticos al uso, algunos de los cuales he citado, reconocen la presencia de funciones externas en tales textos, ninguno ha llegado a mi atención que las adjudique la centralidad que requiere mi propuesta metodológica. Es cierto que un método basado en la identificación de las funciones textuales externas resulta poco fértil aplicado a algunos géneros teatrales concretos - verbigracia, al teatro del absurdo-, pero las comedias de enredo calderonianas se encuentran en el extremo opuesto de la escala. Precisamente aquello que las define - la priorización de la construcción de un complejísimo enredo, y el imperativo de vencer eficazmente la dificultad de hacer inteligible y mínimamente plausible este enredo para el espectador - vuelve especialmente predominantes y transparentes en sus textos las funciones externas.

Digámoslo de otra manera. La finalidad artística principal de las comedias de enredo es crear situaciones cargadas de ironía cómica que provocan el regocijo del espectador. No es que nos riamos de los personajes; nos reímos asistiendo a la perplejidad que estos deben sentir ante situaciones que hemos visto producirse y que sabemos inexplicables para ellos. Hacer que se produzcan estas situaciones dentro de las limitadas coordenadas de una representación teatral, conseguir que sean representables sobre un escenario e inteligibles para los espectadores,

${ }^{7}$ Ingarden, 1958, p. 165. 
dándoles a la vez un barniz de verosimilitud, constituyen un reto formidable para el poeta dramático. Los textos de las comedias de enredo de Calderón evidencian, en efecto, que acostumbraba poner todos o casi todos los recursos al servicio de este reto. Por ello considero especialmente aplicable a este tipo de obras teatrales el método de análisis que ejemplificaré en estas páginas, ofreciendo un muestrario de las técnicas empleadas por Calderón para armonizar las funciones externa e interna en sus comedias de enredo.

\section{Definir el LUgar DE ACCIÓN}

La llegada a un lugar es la situación predilecta en Calderón para iniciar la acción dramática, y ofrece, por supuesto, una oportunidad de oro para deslizar en el diálogo una mención del lugar de acción, a menudo en el incipit. Una opción aceptable para la retórica de la época es el apóstrofe, como el de Rugero en los primeros versos de Lances de Amor y Fortuna ("iGracias a Dios que he llegado, / noble Barcelona, a verte!», p. 667), que expresa la alegría de la llegada después de un largo viaje. Los versos iniciales de El escondido y la tapada relegan el lugar de acción a una frase subordinada («Pues no podemos entrar / en Madrid...”, p. 675), y en los de El acaso y el error lo exaltan («En tanto que los caballos / descansan, ver solicito / este parque del Alcázar / de Módena», p. 713). El hombre pobre todo es trazas empieza con la llegada de Rodrigo a la posada donde se aloja don Diego y las quejas del criado por haber tardado «tres horas» en encontrarla, lo cual justifica el siguiente intercambio que permite una alusión discreta al lugar de acción (p. 653):

Diego

Pues, cuando

te escribí, ¿no te avisé

de la calle?

RODRIGO

¡Lindo talle!

En Madrid ¿no es cosa llana, señor, que de hoy a mañana suele perderse una calle?

Versos que, por supuesto, también sirven para ponernos en situación, haciéndonos saber que Rodrigo ha venido a Madrid a petición de don Diego en una carta. La banda y la flor, finalmente, empieza así: 


$\begin{array}{ll}\text { ENRIQUE } & \begin{array}{l}\text { ¡Que alegre cosa es volver, } \\ \text { después de una gran partida, } \\ \text { a ver la patria! En mi vida } \\ \text { tuve tan grande placer. }\end{array} \\ & \text { Ni yo tan grande pesar, } \\ \text { Pues después de tanta ausencia, } \\ \text { hoy a vista de Florencia } \\ \text { nos quedamos, sin llegar } \\ \text { a saber lo que hay de nuevo (p. 424). }\end{array}$

Los versos de Ponleví en los que Calderón desliza la alusión al lugar de acción, sirven a su vez para justificar las explicaciones de Enrique que siguen a continuación y en los que expone los motivos de su retorno a Florencia, gracias a lo cual el espectador se entera del triángulo amoroso que conformará el núcleo de la acción dramática.

Si no se menciona el lugar de acción en el incipit, Calderón suele aprovechar la primera oportunidad que se le ofrece para insertar una referencia al mismo. En la escena inicial de Para vencer amor, querer vencerle, don César pide a don Carlos que organice «algún festejo [...] hoy en Ferrara»; y en la de Mañanas de abril y mayo, don Pedro exclama a su amigo don Juan: «¿Cómo os atrevéis a entrar / así en Madrid?» (p. 256). No carece de sutileza la justificación de la alusión a los dos lugares de acción en de Casa con dos puertas mala es de guardar, en una referencia a una supuesta conversación anterior que los espectadores, desde luego, ignoran:

\author{
¿No me dijisteis anoche \\ que a dar unos memoriales \\ habíais de ir a Aranjuez? \\ Pues ¿cómo a Ocaña os tornasteis \\ desde el camino? (p. 121).
}

\title{
IDENTIFICAR A LOS PERSONAJES
}

Es crucial conseguir que el público identifique a cada actor con su personaje correspondiente, tarea que se vuelve más hacedera si se dosifica su aparición en escena. El primer acto puede ser descrito en muchos casos como la dosificada presentación de los personajes y de las relaciones entre ellos. El caso de La vida es sueño es modélico en esto, pero nos puede servir de ejemplo casi cualquier comedia. En Con 
quien vengo, vengo, Calderón nos hace presenciar primero una discusión entre las dos damas, en seguida identificadas como hermanas, Leonor y Lisarda. Su diálogo concluye con la llegada de la criada y del criado. Un poco más tarde, sale su hermano Sancho en escena. Se produce lo que ahora sería un "oscuro» y salen los dos galanes que se acabarán casando con Leonor y Lisarda, don Juan y Octavio. Más tarde se une a ellos el padre de don Juan, Ursino. El final del acto reúne a todos los personajes principales en casa de las damas. Así, en parejas, o de uno en uno, suele presentar Calderón a sus personajes principales para que el público los vaya conociendo y no confundiendo. Para identificarlos y diferenciarlos sin peligro de confundirlos — sobre todo en comedias cuya comicidad situacional suele residir en confusiones de identidad-, le conviene al público saber sus nombres, otra información que el poeta ha de deslizar en los textos sin que resulte forzado. También para esta tarea Calderón aprovecha a menudo los versos iniciales. Sirva esta vez de ejemplo único el inicio de Fuego de Dios en el querer bien, en el que son mencionados por su nombre ya tres personajes principales, se esbozan las relaciones entre ellos, se insinúa el especial interés de Álvaro por Beatriz y se anticipan elementos de la acción:

Álvaro

$$
\begin{aligned}
& \text { Preguntando a una criada } \\
& \text { que quién era la visita } \\
& \text { que esperas, me respondió } \\
& \text { que es doña Beatriz de Silva. }
\end{aligned}
$$

Ángela Es verdad, a verme viene esta tarde.

Álvaro

$$
\text { Yo querría, }
$$
como hermano y tu amante, pedirte, Ángela divina, una licencia.

ÁNGELA

Si es

para lo que mi malicia ha discurrido otras veces, no quiero, Álvaro, que digas que como amante, pues basta que como hermano la pidas (p. 1250).

El empleo de los vocativos es frecuente en el inicio de la obra, cuando urge informar al público de la identidad de los personajes, pero se 
repite a menudo en otros lugares del texto: nunca viene mal ayudar al espectador despistado, por lo que es una buena solución para «rellenar» el silabeo del verso. Cabe mencionar aquí también un caso como el del inicio de Los cabellos de Absalón, que por ser una escena coral dificulta al público la tarea de diferenciar rápidamente entre los personajes; de modo que Calderón hace que el Rey David se dirija a cada uno de sus hijos presentes con un vocativo no una sino dos veces (vv. 23-34 y 6373).

\section{CARACTERIZACión}

Es manifiesto, en resumen, el cuidado que pone Calderón desde el principio de las comedias en ponerles nombre a los personajes y en esbozar sus relaciones de parentesco, amistad o de diferenciación social. Menor es su esfuerzo, al menos en las comedias de enredo, para aportar elementos de caracterización individualizada. Una de las excepciones a esta regla la ofrecen los versos iniciales de De una causa, dos efectos. No es fortuito que se trate precisamente de una comedia construida en torno a la oposición de caracteres entre dos hermanos, el estudioso Carlos y el frívolo Fadrique. Empieza así:

Federico ¿Qué hace Carlos?

ENRIQUE

Todo el día

encerrado con Platón

y Aristóteles (que son

luz de la filosofía)

se ha estado (p. 551).

En seguida sale otro criado, Marcelo, y se produce este intercambio:

Federico

Marcelo.

Marcelo

¿Qué mandas?

Federico

Di,

¿qué hace Fadrique?

MarCelo

Señor,

ahí le dejo entretenido

con un juglar que ha venido

a Mantua, de extraño humor: 
haciendo burlas con él

toda la mañana ha estado (p. 552).

Con esto, ya sabemos no sólo cómo se llaman los dos hermanos, sino también, más importante, cómo contrastan sus estilos de vida — tan opuestos como son las ocupaciones de un filósofo y de un juglar-, hecho que el padre se encargará de remarcar además en sus comentarios. Todo ello viene ya recogido en el título de la comedia, siendo el padre la «causa» de la que sus dos hijos son los «efectos» opuestos. La caracterización de los personajes se deriva de las exigencias de la acción - atestiguando una vez más la subordinación de aquella a esta en la comedia nueva-, lo mismo que otros casos de caracterización contrastiva y un tanto esquemática, como la de las hermanas Beatriz y Leonor en No hay burlas con el amor o la de Clara y Eugenia en El agua mansa, contrastadas estas últimas ya por los sentimientos que expresan a su llegada a Madrid (nótese, por otra parte, cómo los mismos versos le sirven a Calderón para indicar de pasada el lugar de acción, no nombrado con anterioridad en la comedia):

Clara

Feliz yo que ver alcanzo este día, aunque a pensión de haber, hermana, dejado las paredes del convento.

Eugenia Feliz yo, pues he llegado a ver calles de Madrid sin rejas, redes, ni claustros (vv. 116-122).

Cabe mencionar también la caracterización, en bastantes comedias de Calderón, y ya convencional en Lope de Vega, de la dama impermeable a los sentimientos amorosos, como Lisarda al inicio de Con quien vengo, vengo o Ángela en Fuego de Dios en el querer bien:

¿Hay cosa de mayor risa que ver a un enamorado cómo sus afectos pinta? ¡Pobres dellos, y dichosa yo, que no supe en mi vida lo que es querer bien a nadie, sino libre, ufana, altiva, hacer donaire de todos, 
sin que haya tan atrevida pasión que piense que a mí me avasalle ni me rinda (p. 552).

Es una señal inconfundible para el público de que el personaje está a punto de caer en las redes del amor; también cuando se trata de un galán, como el don Alonso que al inicio de No hay burlas con el amor despide a su criado por haber cometido tal disparate como el de enamorarse. En el fondo, los personajes de la comedia de enredo no precisan de caracterización porque esta forma parte de la fórmula teatral implícita ${ }^{8}$, y sólo cuando los mecanismos del enredo imponen la necesidad de variar sobre el estereotipo, Calderón genera personajes que se apartan de él. Se explica así suficientemente, a mi modo de ver, la creación de figuras como el rústico galán don Toribio de El agua mansa o el mujeriego infiel don Hipólito de Mañanas de abril y mayo.

\section{INFORMAR DE LOS ANTECEDENTES}

Me he centrado, hasta aquí, en los elementos más fácilmente identificables en su función externa, pero no dejan de ser elementos auxiliares de lo más importante: la construcción de la trama.Y es que la exposición dosificada e inteligible del enredo - que suele alcanzar en Calderón, insisto, una complejidad extraordinaria—, constituye sin duda el mayor reto para el poeta, y sin exagerar puede afirmarse que tal tarea consume casi el texto entero de cualquiera de este tipo de comedias. La complejidad impone que a veces una parte importante del enredo ni siquiera se incluya en la acción escénica sino que la anteceda, siendo transmitida al público por narración. Peor está que estaba, por ejemplo, arranca con la lectura de una carta que incluye en tan sólo dos frases la siguiente información:

\footnotetext{
8 «Sus rasgos típicos más acusados son, para el galán, valor, audacia, apostura, linaje, sentido de honor, conocimiento de todos ellos; para la dama linaje, belleza, audacia, ingenio, absoluta dedicación amorosa» (Ruiz Ramón, 2002, p. 158). Alguna inclusión o exclusión en estos inventarios podría discutirse, pero resulta incontrovertible la posibilidad misma de enumerar «los rasgos típicos más acusados» de los protagonistas.
} 
Desta ciudad, por causa de una muerte, se ausenta un caballero, de cuyas señas y nombre os informará ese criado. Lleva consigo una hija mía, que, como cómplice en el primer delito, ha añadido el segundo (p. 863).

Los hechos que recogen estas dos frases hubieran ofrecido acción dramática suficiente para llenar al menos un acto entero, pero Calderón ha optado por resumirlos así para poder dedicar sus tres actos completos a construir la laberíntica confusión de identidades y malentendidos que configurarán la acción de la comedia.

La narración de los antecedentes de la acción, así como otras informaciones necesarias para poner en situación al público, es un ingrediente casi fijo del primer acto de las comedias, habitualmente incluido en forma de un romance que se inserta muy pronto en el texto: la «relación». Se trata, desde luego, de un artificio recurridísimo en la dramaturgia universal: un personaje cuenta a otro personaje cosas que este ignoraba, gracias a lo cual el público también se entera de ellas. Se necesita, pues, a un personaje que ignore los antecedentes, generalmente un amigo, pariente o criado del narrador de los mismos.

Con todo, el destinatario escénico de la información suele disponer de más datos previos que el público, por lo que a menudo no basta con que se le diga lo que ignora: también hay que decirle cosas que ya sabe para que el público las conozca. Por ello, Calderón acude a menudo a un sencillo truco retórico, poniendo en boca de su personaje un preámbulo con la información que ya posee su interlocutor. Así, apenas arrancada la acción de Mejor está que estaba, escuchamos a Flora decir:

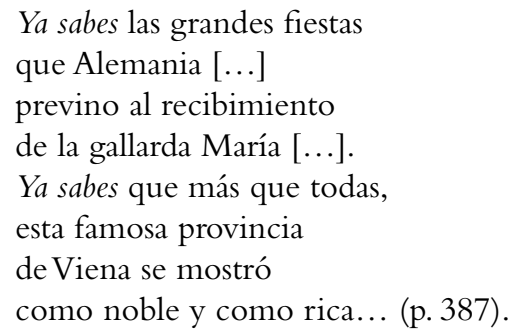

Claro, su interlocutora, Silvia, en efecto, ya sabe estas cosas, pero nosotros, los espectadores, no, y había que hacernos llegar la información. De modo similar prepara Leonor sus explicaciones a Carlos en No siempre lo peor es cierto (p. 1454); y en Dicha y desdicha del nombre (p. 1800), Calderón sólo necesita cinco versos iniciales de la comedia para llegar al «Ya sa- 
béis..., ya sabéis...». Por supuesto, este anafórico «Ya sabes...» cuenta con todo tipo de variantes; cito dos que ocurren en Primero soy yo:

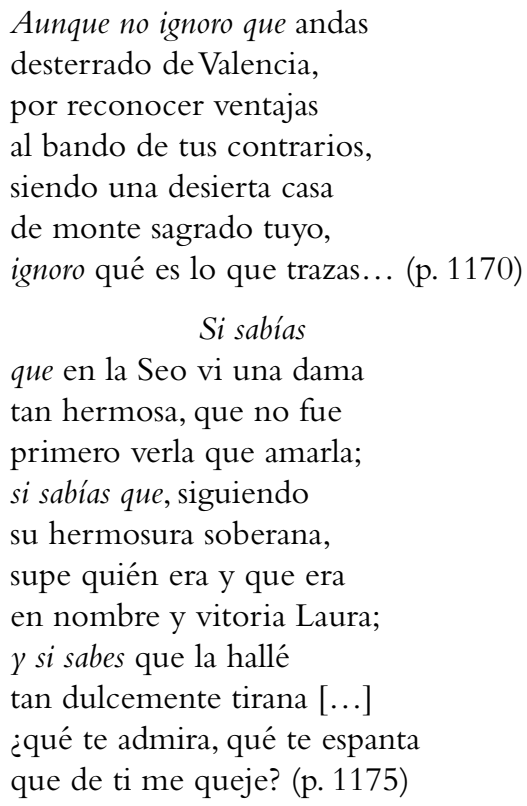

En un pasaje análogo de Las manos blancas no ofenden, Federico interrumpe finalmente su propio discurso para preguntarse: «Mas ¿para qué

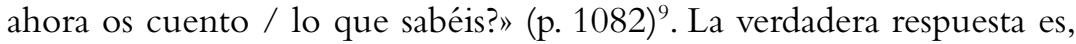
desde luego, que Federico no es más que una marioneta en manos de don Pedro Calderón, que le hace decir lo que le resulte conveniente que diga. A veces, Calderón añade una justificación interna de tales explicaciones destinadas al público. Así, cuando al principio de Basta callar, Margarita acaba de dar detalles de su abolengo a su criada, que por supuesto ya los conoce, añade:

No para desvanecerme mi estirpe te acuerdo clara, sino antes para quejarme de mi fortuna (vv. 13-16).

${ }^{9}$ Compárese, en El mágico prodigioso, «Pero, ¿para qué procuro / contarte lo que ya sabes?» (vv. 2592-2594), o en Duelos de amor y lealtad, "permite que no prosiga / lo que ya sabes» (p. 1467), etc. 
En Antes de todo es mi dama (vv. 103-146), Lisardo propone a Félix que intercambien la narración de sus respectivos sucesos, que ya conocen, para incluir todos los detalles y para consolarse mutuamente («Que los daños, / ya que su mal es sentirlos, / su cura es comunicarlos», vv. 138-140) justificando así dos relaciones que informan al público de los antecedentes. Félix, por su parte, incluye en su discurso la narración de un suceso "que no hace al caso» (v. 180) pero que afirma contar "porque no penséis / que nada en mi pecho guardo" (vv.181-182). Por supuesto, el verdadero motivo, el externo, es que el suceso - el haber reñido en Granada con el tercer galán de la comedia, Antonio- es importante para el argumento de la comedia y el público ha de estar al tanto.

\section{Preparar el enredo}

Una vez identificados el lugar de acción, la identidad de los personajes, las relaciones entre ellos y los antecedentes de la acción escénica, Calderón se puede ir centrando más en la tarea principal de tejer el enredo. El análisis de este aspecto central, empero, exige el examen detallado del texto de una comedia entera, tarea que no puedo emprender aquí, dado que «es casi imposible resumir el argumento de una comedia de enredo» ${ }^{10}$; me limitaré a unos ejemplos fáciles de aislar.

En Con quien vengo, vengo, el detonante de la laberíntica confusión de identidades que se va a producir es el hecho de que Octavio acompañe, disfrazado de criado, a su amigo don Juan cuando este visita a su amada doña Leonor; mientras a esta la acompaña simétricamente su hermana Lisarda, igualmente fingiendo ser criada suya. Lisarda, por supuesto, se enamorará del criado fingido Octavio, y Octavio a su vez de la criada fingida Lisarda. Pues bien, la comedia empieza con Lisarda arrancándole a su hermana de las manos una carta en la que esta le suplica a don Juan «vengáis esta noche por el jardín, donde entraréis a hablarme; $y$ venga con vos el criado, porque cuando yo aventuro mi vida, trato de asegurar la vuestra» (p. 1129, la cursiva es mía). Lo que, en este momento de la obra, puede parecer un detalle insignificante - la solicitud, someramente justificada en el plano interno, de que el galán venga acompañado de su criado- es en realidad una semilla que siembra Calderón para que brote la confusión posterior. En la escena siguiente,

${ }^{10}$ Pedraza Jiménez, 1998, p. 10. 
Octavio acompaña a su amigo Juan cuando este lee la carta de Leonor, y su produce el siguiente diálogo:

Octavio Esta dama os pone a un riesgo

notable, y os da licencia

que, para el seguro vuestro,

llevéis un criado;...

JUAN

Sí.

Octavio

...pues en cualquiera suceso, ¡cuánto es mejor un amigo de satisfacción y esfuerzo!

Yo como vuestro criado

he de ir con vos, pues es cierto

que yo para todo trance

os seré de más provecho.

Anteriormente, Lisarda, ya enterada por la carta de los amores de su hermana, le pregunta quién es la «tercera» de su amor, y cuando Leonor le contesta que es su criada Nise, Lisarda ofrece acompañarla en su lugar, aduciendo la poca fiabilidad de las criadas para guardar secretos (convención de las comedias explotada aquí oportunamente por Calderón para justificar la decisión del personaje), y añade:

\author{
En traje disimulado \\ yo tu criada he de ser \\ de noche $[\ldots]$ \\ Seis cosas así consigo (p. 1131).
}

En efecto, nada menos que seis motivos enumera por los que considera conveniente que acompañe a su hermana disfrazada de criada; pero todos ellos, por supuesto, inventados por Calderón para justificar una decisión cuyo verdadero motivo es ajena a la voluntad del personaje: provocar la otra de las dos suplantaciones de identidad que iniciarán la serie de equivocaciones que, en su conjunto, constituyen la trama de Con quien vengo, vengo. 


\section{JUSTIFICAR PRESENCIAS, AUSENCIAS Y OCULTACIONES}

Conforme va avanzando la acción, son menos necesarios los elementos textuales cuya función externa es poner al público en situación. Paulatinamente, los propios sucesos que se producen en escena ante los ojos del público se van convirtiendo en la principal fuente de información sobre el argumento. Pero sigue siendo necesario suplementar la acción escénica con alusiones textuales a, entre otras cosas, cambios de lugar, saltos temporales, sucesos producidos entre escena y escena o fuera del escenario, y sobre todo, el por qué de las decisiones y acciones de los personajes. A menudo se trata de un breve aparte en el que un personaje motiva una acción dificil de justificar pero necesaria para el desarrollo de la trama ${ }^{11}$. Claros ejemplos se producen en las numerosas ocasiones en las que el enredo exige la presencia o ausencia de un personaje que no tiene un motivo manifiesto para ella. Así, se inicia el acto final de Fuego de Dios en el querer bien con don Juan diciendo esto a su criado Hernando:

Con deseo de saber

la confusión de mi pecho

la diligencia que ha hecho

don Álvaro, vengo a ver

si ya a su casa volvió (p. 1276).

De momento, sin embargo, a Calderón le conviene que sólo el criado entre en la casa de don Álvaro, por lo que hace a don Juan añadir:

Llega, y si está en ella, di,

Hernando, que estoy aquí.

Don Juan se queda esperando "en una esquina». Sólo un poco más adelante, cuando a Calderón le interesa la irrupción de don Juan en escena, le hace justificarlo diciendo "Ya que mis locos recelos / no se excusan de no entrar...» (p. 1277). De nuevo, se trata de un somero intento de dar una apariencia de verosimilitud a los hechos, ante un público que, familiarizado con las convenciones genéricas, no será muy exigente al respecto.

${ }^{11}$ Los apartes realmente no cumplen una función comunicativa interna, es decir, los personajes no tienen motivo alguno para decir lo que dicen. La función de los apartes, sancionada por una convención dramática, es exclusivamente externa. 
Otro ejemplo clarísimo se produce al inicio del tercer acto de Primero soy yo, cuando Calderón necesita justificar la presencia en un mismo espacio de numerosos personajes; la justificación que aduce cada uno de ellos resulta, bien mirado, traída por los pelos. Estando Álvaro sólo, es buscado porVicente, quien se justifica así:

\section{Viendo que ya amanecía y que a la quinta no vienes, con cuidado de saber, Álvaro, qué te detiene, vengo a buscarte (p. 1192).}

Después, Hipólita:

Pues que gente se oye ya en esta antesala, salgo a ver lo que sucede.

Seguida inmediatamente por Laura:

Y yo [salgo a ver] a quien dejó el empeño de sus efectos pendiente.

Finalmente, un poco después, el padre de Laura, Lisardo, «al paño»:

Dos días ha que dejé a Laura.

Mucha ausencia me parece; y así con el día mi amor me trae a verla. Allí hay gente. Sus amos son: no estorbemos. Aquí retirado espere ocasión.

Por supuesto, esta justificación tan endeble para lo que, bien mirado, es una acción harto extravagante - entrar sigilosamente en casa ajena y ocultarse en ella, sin tener intenciones delictivas-, pretende disimular la justificación dramática de esta acción: poner a Lisardo en situación de poder oír cosas no destinadas para sus oídos. En efecto, en seguida tendrá motivos para exclamar «QQue a ocasión de oír esto llegue!» y salir indignado de su escondite. Hay innumerables casos comparables en Calderón. 


\section{IMPEDIR EL RECONOCIMIENTO}

Ya señaló Mason el elevado número de «escenas de noche, que desde luego se presentaban por la tarde al pleno sol» y lo explicaba por «la ventaja de que los personajes no pueden reconocerse unos a otros en la oscuridad» ${ }^{12}$. Se diría incluso que es este el motivo por el que se crean estas escenas, y que es por el mismo motivo que sus comedias están pobladas de damas tapadas e igualmente irreconocibles; al menos, según las convenciones de la comedia, puesto que todos sabemos que, en el mundo real, hay pocos atributos tan inconfundibles en los individuos como su voz. En el tercer acto de Con quien vengo, vengo, Ursino alude tres veces a la oscuridad mientras se produce un trueque de damas inadvertido por los hombres que las acompañan:

Mucho me huelgo que esté sin luz el portal ahora:

Como está

la casa sin luz, no veo.

Pues, ¿cómo sin luz

estáis en este portal? (p. 1156)

En cambio, cuando el enredo así lo requiere, desaparece la dificultad del reconocimiento. En la misma comedia, Octavio — quien se ha enamorado de Lisarda durante sus conversaciones nocturnas sin haberla visto nunca- al llegar a verla vestida como dama, la toma por su hermana Leonor sin reconocer la voz de su amante; pero un poco antes, el criado Celio reconoce a la misma Lisarda inmediatamente por su voz sin verla y a pesar de que ella está fingiendo ser Nise; Calderón pone en su boca una justificación de este reconocimiento, como si se tratara de un hecho sorprendente:

Lisarda (a quien conozco

por la voz distintamente, como aquel que de la suya y de la de Nise tiene más noticia) me ha llamado por mi nombre. (p. 1148)

${ }^{12}$ Mason, 1976, p. 100.Ver también Satake, 2002. 
Del mismo modo, cuando así resulta oportuno para encadenar los sucesos, Octavio reconoce la voz de Juan ("Aquella voz / conozco, salir pretendo", p. 1151), y en otro momento, Leonor hace lo mismo («Nueva maravilla ya / admiro: de don Juan fue / aquella voz», p. 1156). En fin, también en esto, las exigencias de la acción imponen su lógica sobre lo demás.

\section{REFLEXIÓN FINAL}

No me atrevería a afirmar haber ofrecido aquí un inventario exhaustivo de las funciones externas en los textos de las comedias de enredo. He omitido, para empezar, las relacionadas con el mero deleite verbal que genera el texto, y que habría que incluir decididamente entre las funciones externas, puesto que - dejando a un lado algún guiño metaliterario de los graciosos - los personajes, desde luego, no saben que hablan en verso ni tienen conciencia de sus anáforas, quiasmos y antítesis ${ }^{13}$. Tampoco he querido entrar, por ejemplo, en la función parcial que parecen tener algunas «relaciones», de entretener al público con una narración de episodios novelescos no estrictamente relevantes para el enredo. Algunas de las funciones que sí he comentado, como la identificación del lugar de acción y de los personajes, pueden considerarse menores o subsidiarias frente a las relacionadas con la acción propiamente dicha, pero me ha parecido útil demostrar que Calderón las emplea de forma muy consciente y meditada. Finalmente, el análisis de las realmente importantes, aquellas que contribuyen directamente a la urdidura del enredo de cualquier comedia individual, exige conectar varios lugares del texto y momentos de la acción, así como aislar múltiples funciones externas dentro de un mismo pasaje. Esta labor, que sólo puede ser llevada a cabo adecuadamente analizando minuciosamente el texto de la comedia entera, es, a mi juicio, imprescindible para evitar grandes errores a la hora de prepararlo o adaptarlo para su puesta en escena.

${ }^{13}$ En palabras de García Barrientos, «los personajes que hablan en verso "ignoran” por convención la forma métrica en que se expresan», ya que su lenguaje "es percibido por ellos, en el interior de su mundo, como neutro o normal, como si fueran sordos a los valores formales, retóricos, literarios, que también por convención van destinados a impresionar sólo al público, a causar sólo en él sus efectos» (2007, pp. 53 y 61). 


\section{BiBLIOGRAFÍA}

Calderón de la Barca, Pedro, Antes que todo es mi dama, ed. Bernard P. E. Bentley, Kassel, Reichenberger, 2000.

Calderón de la Barca, Pedro, Basta callar, ed. Margaret Greer, Ottawa, Dovehouse, 2000.

Calderón de la Barca, Pedro, Casa con dos puertas, mala es de guardar, en Comedias, I. Primera parte de comedias, Madrid, ed. Luis Iglesias Feijoo, Castro, 2006.

Calderón de la Barca, Pedro, Con quien vengo, vengo, en Obras completas. Comedias, ed. Ángel Valbuena Briones, Madrid, Aguilar, 1960.

Calderón de la Barca, Pedro, Dicha y desdicha del nombre, en Obras completas. Comedias, ed. Ángel Valbuena Briones, Madrid, Aguilar, 1960.

Calderón de la BARCA, Pedro, Duelos de amor y lealtad, en Obras completas. Dramas, ed. Ángel Valbuena Briones, Madrid, Aguilar, 1987.

Calderón de la Barca, Pedro, El acaso y el error, en Obras completas. Comedias, ed. Ángel Valbuena Briones, Madrid, Aguilar, 1960.

Calderón de la BArCA, Pedro, El agua mansa, en El agua mansa / Guárdate del agua mansa, ed. Ignacio Arellano yVíctor García Ruiz, Kassel, Reichenberger, 1989.

Calderón de la Barca, Pedro, El escondido y la tapada, en Obras completas. Comedias, ed. Ángel Valbuena Briones, Madrid, Aguilar, 1960.

Calderón de la Barca, Pedro, El mágico prodigioso, ed. Bruce W. Wardropper, Madrid, Cátedra, 1985.

Calderón de la Barca, Pedro, Fuego de Dios en el querer bien, en Obras completas. Comedias, ed. Ángel Valbuena Briones, Madrid, Aguilar, 1960.

Calderón de la Barca, Pedro, Hombre pobre todo es trazas, en Comedias, II. Segunda parte de comedias, ed. Santiago Fernández Mosquera, Madrid, Castro, 2006.

Calderón de la Barca, Pedro, La banda y la flor, en Obras completas. Comedias, ed. Á.Valbuena Briones, Madrid, Aguilar, 1960.

Calderón de la Barca, Pedro, La vida es sueño, ed. Ciriaco Morón, Madrid, Cátedra, 1985.

Calderón de la Barca, Pedro, Lances de amor y fortuna, en Comedias, I. Primera parte de comedias, ed. Luis Iglesias Feijoo, Madrid, Castro, 2006.

Calderón de la Barca, Pedro, Las manos blancas no ofenden, en Obras completas. Comedias, ed. Ángel Valbuena Briones, Madrid, Aguilar, 1960.

Calderón de la Barca, Pedro, Los cabellos de Absalón, ed. Evangelina Rodríguez Cuadros, Madrid, Espasa Calpe, 1989.

Calderón de la Barca, Pedro, Mañanas de abril y mayo, en Comedias, III. Tercera parte de comedias, ed. Don W. Cruickshank, Madrid, Castro, 2007. 
Calderón de la Barca, Pedro, Mejor está que estaba, en Obras completas. Comedias, ed. Ángel Valbuena Briones, Madrid, Aguilar, 1960.

Calderón de la Barca, Pedro, No hay burlas con el amor, ed. y trad. Don W. Cruickshank y S. Page, Warminster, Aris \& Philips, 1994.

Calderón de la Barca, Pedro, No siempre lo peor es cierto, en Obras completas. Comedias, ed. Ángel Valbuena Briones, Madrid, Aguilar, 1960.

Calderón de la Barca, Pedro, Para vencer amor, querer vencerle, en Obras completas. Comedias, ed. Ángel Valbuena Briones, Madrid, Aguilar, 1960.

Calderón de la Barca, Pedro, Peor está que estaba, en Comedias, I. Primera parte de comedias, ed. Luis Iglesias Feijoo, Madrid, Castro, 2006.

Calderón de la Barca, Pedro, Primero soy yo, en Obras completas. Comedias, ed. Ángel Valbuena Briones, Madrid, Aguilar, 1960.

Coenen, Erik, «Sobre el texto de Darlo todo y no dar nada y la transmisión textual de las comedias de Calderón", Criticón, 102, 2008, pp. 195-209.

García Barrientos, José Luis, Cómo se comenta una obra de teatro, Madrid, Síntesis, 2003.

IngARDEN, Roman, «Las funciones del lenguaje en el teatro» [1958], en Teoría del teatro, comp. María del Carmen Bobes Naves, Madrid, Arco, 1997, pp. 155-165.

Mason, T. R. A., «Los recursos cómicos de Calderón», en Hacia Calderón. Actas del III Coloquio Anglogermano, Berlin / New York, Walter de Gruyter, 1976, pp. 99-109.

Pedraza Jiménez, Felipe B., «Palabras preliminares», en La comedia de enredo. Actas de las XX Jornadas de teatro clásico. Almagro, Almagro, Universidad de Castilla-La Mancha / Festival de Almagro, 1998, pp. 7-11.

Ruiz Ramón, Francisco, "Calderón, un autor en busca de público», en Calderón 2000, ed. Ignacio Arellano, Kassel, Reichenberger, 2002, vol. I, pp. 151-162.

SATAKE, Kenichi, «Efectos de la oscuridad en algunas comedias de capa y espada de Calderón», en Calderón 2000, ed. Ignacio Arellano, Kassel, Reichenberger, 2002, vol. I, pp. 1141-1154.

Serralta, Frédéric, «El enredo y la comedia. Deslinde preliminar», Criticón, 42, 1988, pp. 125-137.

SPANG, Kurt, Teoría del drama. Lectura y análisis de la obra teatral, Pamplona, Eunsa, 1991.

Trancón, Santiago, Teoría del teatro, Madrid, Fundamentos, 2006.

Ubersfeld, Anne, El diálogo teatral, trad. Armida María Córdoba, Buenos Aires, Galerna, 2004. 